\title{
Determinants of Consumer Purchase Decision Making for Fast Moving Consumer Goods
}

\author{
V. M. Dibie; E. L. Unanam A. O. Nwakwue K. U. Kalu \\ Department of Marketing, College of Management Sciences, Michael Okpara University of Agriculture, \\ Umudike
}

\begin{abstract}
The study examined the determinants of consumer purchase decision making for fast moving consumer goods with the British American Tobacco Company's products. Specifically, the study analyzed the psychological factors affecting consumer purchase decision making for FMCGs and determined the social factors affecting consumer purchase decision making for FMCGs. Through survey design, the study adopted a sample of 30 selected students of Michael Okpara University of Agriculture Umudike using random sampling technique, in effect, 30 questionnaires were distributed and recouped from the respondents. Primary data sourced from distribution of the copies of the questionnaires to students of Michael Okpara University of Agriculture Umudike were used for the study. A test-re-test was conducted to ensure validity and reliability of the data. The data were presented using simple percentage, frequency and 5point Likert scale. The hypotheses were tested using multiple regression model (SPSS version 20). The result reveal motivation and attitudes have positive and significant impact on turnover of fast moving goods; while personality and learning significant impact on turnover of fast moving goods. However, perception has positive and insignificant impact on turnover of fast moving goods in British American Tobacco Company in Nigeria. In addition, Social class, reference group, family have positive and significant impact on turnover of British American Tobacco Company fast moving products; while culture/belief negative and significant impact on turnover of fast moving goods. However, opinion leaders has negative and insignificant impact on turnover of fast moving goods in British American Tobacco Company in Nigeria. It was recommended that marketers of this products need study the critical factors affecting consumer purchase decision making in order to satisfy, retain and maintain the ultimate and prospective consumers.
\end{abstract}

DOI: $10.7176 /$ RHSS/9-11-02

Publication date:June $30^{\text {th }} 2019$

\section{Introduction}

In this era of post liberalization, the market scenario in Nigeria has witnessed intense market competition and proliferation of brands in most sectors of the economy especially in fast moving consumer goods (FMCGs). Understanding consumer purchass decision making is of vital interest for any business operating under a clearly defined FMCGs (Berry, 2010). FMCGs are popularly named as consumer packaged goods. Items in this category include all consumables (other than groceries/pulses) people buy at regular intervals. FMCGs industry primarily deals with the production, distribution and marketing of consumer packaged goods. These are products that have a quick turnover; and bought at relatively low costs. The industry also engaged in operations, supply chain, production and general management. The most common in the list are toilet soaps, detergents, shampoos, toothpaste, shaving products, shoe polish, packaged foodstuff and household accessories; and extends to certain electronic goods. These items are meant for daily or frequent consumption and have a high return. Consumers generally put less thought into the purchase of FMCGs than they do for other products. Though the absolute profit made on FMCGs products is relatively small, they generally sell in large numbers and so the cumulative profit on such products can be large (Agarwal, 2013).

Moreover, FMCGs industry includes food and non-food everyday consumer products. They are usually purchased as an outcome of small-scale consumer decision (Solomon and Nancy, 2014). They are heavily supported by advertising and other promotional activities by the manufacturers. FMCGs form a major component of total purchases for most consumers. Consumer behaviour is the study of individuals, groups, or organizations and the processes they use to select, secure, and dispose products, services, experiences, or ideas to satisfy needs and the impacts that these processes have on the consumer and society (Kotler and Armstrong, 2010). Consumer behaviour is defined as activities people undertake when obtaining, consuming, and disposing products and services (Blackwell et al., 2001). The study of consumer behaviour does not only include reasons for buying but also the consumption process after buying. Consumers get driven by influences such as feelings, motivation, income, lifestyle, opinions, culture, personality, Social class, reference group, family, opinion leaders, culture/belief etc (Srivastava, 2013).

The decision making of the consumer is determined by the pre purchase behavior, which is preceded by the intention to buy/consume and a host of other antecedent factors. Some of these factors are intrinsic to the consumer like the personal aspects -beliefs/evaluation based attitude towards the act (purchase), while the extrinsic variables like social aspects- subjective norms and the perceived /actual control etc., conditioned within 
the situational construct, influence consumer behavioural intention.

\section{Statement of the Problem}

Everybody is a consumers, one way or the other, consuming one product or the daily or frequently, according to needs, preferences and buying power. These can be consumable goods, durable goods and specialty goods. What we buy, how we buy, where and when we buy; and how much quantity we buy depends on our perception, selfconcept, social and cultural background and our age and family cycle, our attitudes, beliefs values, motivation, personality, social class and many other factors that are both internal and external to us. While buying, we also consider whether to buy or not to buy; and from which source or seller to buy.

The marketer therefore tries to understand the needs of different consumers in different environment to plan and execute effective marketing programmes. Although consumers are very sensitive due to changes in environment factors but it is not always the case in FMCGs because their consumptions are merely driven by some factors, like feelings, motivation, lifestyle, opinions, culture, personality, social class, reference group, family, opinion leaders, culture/belief. Nowadays, so many concerns are rising about the food safety; genetically modified food (GMO) for example. Consumers are therefore more cautious on their spending. Consumers around the world are different in various factors such as age, income, education level and preferences all of which affects their purchase and consumption behaviour for goods and services. Marketers study the behaviour of the different consumer group for different product and services to know what to present to them.

Consumer behavior is a widely studied field. Understanding it completely is impossible, because it is related so closely to human mind. However, forecasting how a human being behaves in buying situations can be estimated through previous purchase decisions. Consumers make buying decisions every day and many people do not even know the factors that drive them to this decision. Buying a coffee/sachet water comes almost automatically and does not need much information search. There are characteristics behind every buying decision that can come from cultural, social, personal or psychological factors. Each of these factors includes dimensions that can be used in marketing. Marketers can use these factors intelligently that consumers might not even recognize how they have been used. Against the background, this study examined the determinants of consumer purchase decision making for fast moving consumer goods.

\section{Objectives of the Study}

The broad objective of this study was to examine the determinants of consumer purchase decision making for fast moving consumer goods with the British American Tobacco Company products in firms. However, the specific objectives were to:

i. analyze the psychological factors affecting consumer purchase decision making for FMCGs

ii. determine the social factors affecting consumer purchase decision making for FMCGs

\section{Research Questions}

Key research questions for the study were:

1. What are the psychological factors affecting consumer purchase decision making for FMCGs?

2. How does social factors affect consumer purchase decision making for FMCGs?

\section{Research Hypotheses}

Hypotheses tested in the course of the study were:

$\mathbf{H}_{01}$ : Motivation, personality, perception, attitudes, learning have no significant impact on consumer purchase decision making for FMCGs?

$\mathbf{H}_{02}$ : Social class, reference group, family, opinion leaders, culture/belief have no significant impact on consumer purchase decision making for FMCGs?

\section{Review of Related Literature Conceptual Framework}

The term consumer behaviour is defined as the behaviour that consumers displays in searching, purchasing, evaluating and disposing of products and services that they expect will satisfy their needs (Blackwell et al., 2001). The modern day marketing discussion centres marketing to be consumer oriented and to be concerned with the needs and wishes of the consumer needs, where studying consumer behaviour is very critical, for companies, to term how these needs can be used (Agarwal, 2013).

The consumer is considered king in today's scenario of marketing. It is the consumer whose buying preferences decide what should be manufactured, both in quantity and in quality. Thus a marketer has to take into account various factors while deciding on which product to market as consumers have different preferences at different point in time. So the task of manufacturers and marketers become onerous; and thereby reemphasizing the need to understand the consumer behavior (Berry, 2010). 
Kundi (2008) stated that consumer behavior refers to the mental and emotional process and the observable behavior of consumers during searching, purchasing and post consumption of a product or service. Consumer behavior blends with elements from psychology, sociology, socio-psychology, anthropology and economics basically. Consumer behavior which was earlier termed covered behaviour is a continuous consumption process related to pre-purchase, purchase and post purchase issues. This refers to the physical action of consumers that can be directly observed and measured by others (Singh and Singh, 2016).

Solomon and Nancy (2014) asserted that, consumer behavior is the study of the process involved when individuals or groups, select, purchase, use or dispose products, services, ideas or experiences to satisfied need and desires.

Consumer behaviour is the study of human or consumer responses to product, services and the marketing of products and services (Frank, 2012). The concept of modern consumer behavior is that people mostly buy products not for what they do but, what they stand for. This concept implies that the products play some roles which go beyond their basic functions; and consumers tend to establish a relationships with a products what they like. The types of relationship a consumer may establish with a product may take the form of self-concept attachment, nostalgic attachment, interdependent and love (Solomon and Nancy, 2014).

Sproles and Kendall (2006) established a model to conceptualize consumers decision making behavior with eight consumer mental orientation variables; viz., perfectionism, consciousness, brand consciousness, novelty and fashion conciseness, impulsive and careless consumer, confused by over choice consumer, habitual and brand loyal consumer, recreational and hedonic shopping conciseness, price and value conciseness.

\section{Factors Affecting Consumers' Purchasing Decision}

Consumers seek items to satisfy their basic needs and desires. Consumer behaviour is much more than studying what consumers buy. It attempts to understand how the decision-making process goes and how it affects consumers' buying behaviour (Frank, 2012). Marketers study consumers buying patterns, to solve the problems of where they buy, what they buy and why they buy. However, why consumers buy a specific product is not easy to solve because the answer is locked deep within the consumers' mind (Kotler and Armstrong, 2010).

Generally consumers can be categorized into individual and organizational consumers. Individual consumers try to satisfy their own needs and wants by purchasing for themselves or satisfy the need of others by buying for them. These individual consumers can come from different backgrounds, ages and life stages (Kardes et al., 2011). A consumer's buying behavior is influenced by cultural, social, personal and psychological factors. Consumer behavior is a part of human behavior and by studying previous buying behavior, marketers can estimate how consumers might behave in the future when making purchasing decisions (Kotler and Armstrong 2010).

The social, personal and psychological characteristics of consumer behavior. a. Social Factors and Consumer Behaviour.

Every individual has someone around influencing his buying decisions. The important social factors are; reference groups, family, role and status (Perreau, 2014).

Every consumer as an individual belong to a group. The group to which a consumer belongs is called a membership group. This is a direct and simple classification. The second group type is a reference group. The reference group influences the self-image of consumers and consumers' behaviour. The reference group provides some points of comparison to consumers about their behaviour, lifestyle or habits. Usually, there are many smaller reference groups, which are formed by family, close friends, neighbours, work groups or other people that consumers associate with. The groups to which a consumer does not belong to yet can also influence him. These aspirational groups are groups where a consumer aspires to belong and wants to be part of in the future (Kotler and Armstrong, 2010).

Family members can influence an individual consumer's buying behaviour. A family forms the environment for an individual to acquire values, develop and shape personality. This environment offers the possibility to develop attitudes and opinions toward several subjects such as social relations, society and politics. A family creates first perceptions about brands or products and consumer habits (Khan, 2006). For example, the consumers who had created brand perceptions when they were young, can apply such perceptions when matters as adult without even recognizing that their family influenced such perceptions them. Individuals play many different roles in the different groups they belong to. Each role consists of activities and attitudes that are expected from an individual to perform according to the persons around him.

Social status reflects the position that individuals have in social groups based on such things as money and wealth, education or occupation. In many societies, status is important and people want the admiration of others. Social status can be acquired by being successful in life or being born into a rich family. Product and brand selection sometimes reflect the social role and status of the individual (Wright, 2016). 


\section{b. Personal factors}

An individual's decisions are influenced by personal factors such as age and life cycle stage, occupation, economic situation, lifestyle, and personality and self-concept. Moreover, environment, values, lifestyle, hobbies and consumer habits evolve during lifetime. Family life stages change purchase behavior and brand selection. Traditionally, a family life cycle included only young singles and married couples with children. Nowadays marketers are focusing on alternative, non-traditional stages, such as unmarried couples, childless couples, same sex couples, single parents and singles marrying later in life (Kotler and Armstrong, 2010). It can be assumed that consumers' taste can change during lifetime and can influence on brand selection at different stages of life.

A consumer's occupation and purchasing power influence his purchase decisions and buying behavior. The income level affects what consumers can afford and the perspective towards money. People, who share similar occupations, tend to have similar taste in music, clothing and leisure activities. They usually socialize with each other, and share the same kind of values and ideas. Income level affects what a consumer can afford as well as his spending habit (Solomon, 2014). Individuals from lower income groups are probably more interested in buying products that are necessary for survival than spending on luxury brands or designer clothes.

A consumers' life style tell how the consumer lives and spends. The product choices that the consumer make are related to their lifestyles. An individual's lifestyle consists of different life style dimensions (Khan, 2006). These dimensions are:

i. activities describe how consumers spends their time, e.g. work, hobbies or vacations;

ii. interests are consumers' preferences and priorities e.g. family, home or food; and

iii. opinions tell how consumers feel about different issues, e.g. themselves, politics or products (Plummer 1974).

These life style dimensions express a person's pattern of living. Lifestyle will influence consumers' buying behavior and decisions (Kotler and Armstrong, 2010). Personality distinguishes one person from another by individual traits. These individual traits can be self-confidence, adaptability, sociability and dominance. Personality determines how we see ourselves and the world around us as well as how other people see us. Attitudes, values and people around us shape our personality. Personality alters during life when a person grows up and changes surroundings (Wright, 2016).

\section{c. Psychological factors}

A buyer's choices are also influenced by four psychological factors, viz: motivation, perception, learning, and beliefs. A consumer is an individual who has different kind of needs. These needs can be biological like thirst or psychological arising from the need of recognition or belonging. A need can be aroused to a sufficient level of intensity when it alters a motive. A motive is basically a need that drives a person to seek satisfaction. Abraham Maslow is probably the most renowned psychologist who has examined these human needs critically. He sought to explain why humans are driven by different needs at different times (Kotler and Armstrong, 2010).

Maslow's hierarchy of needs has the most pressing at the bottom and the least pressing at the top. The basic rule is to satisfy the basic need first, before proceeding up the ladder. When that need has been fulfilled, it stops being a motivator and a person focuses on the next most important need. Maslow's needs are:

1. Physiological: basic need such as sleep, food or water.

2. Safety: need to feel secured and protected.

3. Belongingness: need to feel loved and be accepted by others.

4. Ego needs: to accomplish something and have status among others.

5. Self-actualization: to have enriching experiences and feel self-fulfillment.

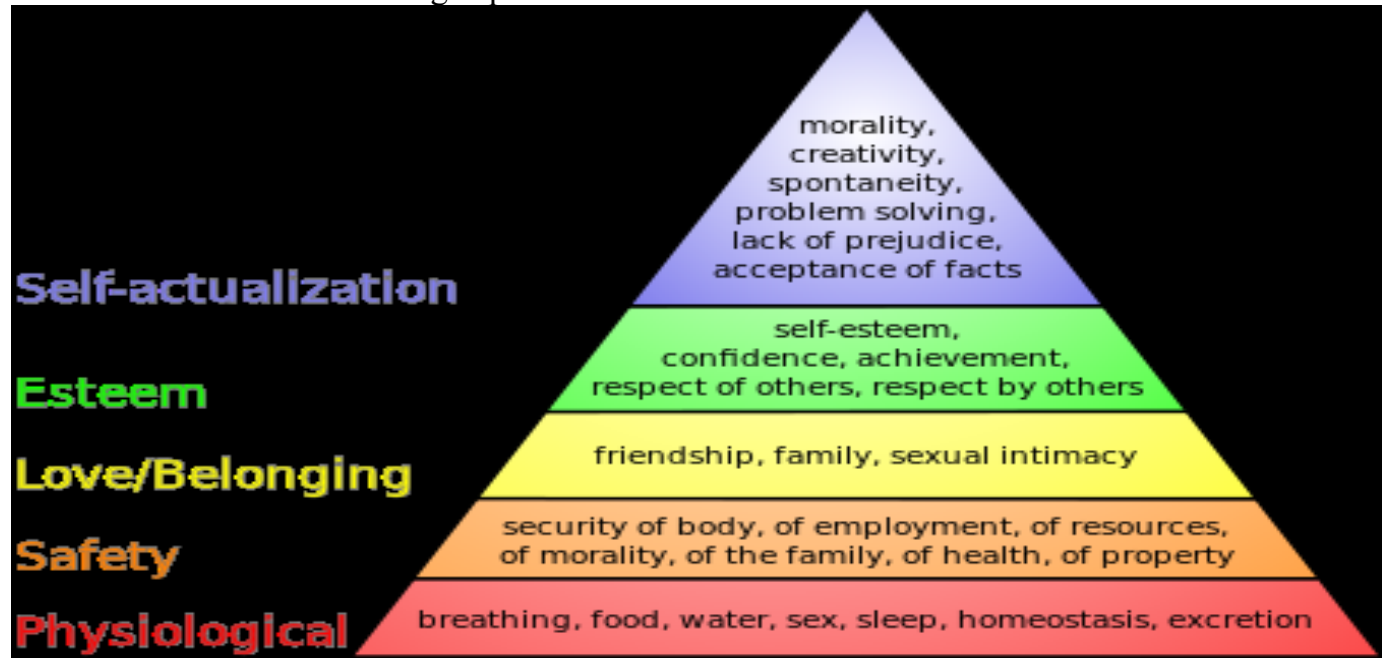

Figure 2.1 Abraham Maslow Theory of Needs; Source: Tanja (2015). 


\section{d. Cultural Factors: -}

Culture is the fundamental determinant of a person's conservation and consuption. Companies often design specialized marketing programs to serve each subculture. This programme is called diversity marketing. The effect of culture upon a consumer's behaviour is considerable, and culture is a factor which has the greatest influence (Agarwal, 2013). Culture creates the foundation of the individual's values, opinions and behaviour, and is learnt from the other members of society or from school and institutions that play a significant part of one's environment and these traits constitute what the consumer values, wants are and therefore do affect the way consumer acts. Culture also consists of different subcultures that group people by their nationality, ethnicity, geographic location, religious views or by their set of shared values. By targeting members of a specific culture or sub-culture, businesses can tailor their marketing mix to match the needs and values of that segment (Kotler $e t$ al., 2005).

\section{Concept of Fast Moving Consumer Goods}

Fast Moving consumer goods are those goods that are consumed every day by the average consumer and are replaced or fully used up over a short period of days, weeks, or months, and within one year. The Fast Moving Consumer Goods (FMCG), also known as Consumer Packaged Goods (CPG), is products that have a quick turnover and relatively low cost. Though the absolute profit made on FMCGs is relatively small, they generally sell in large numbers and so the cumulative profit on such products can be large.

Fast moving consumer goods have a short shelf life, either as a result of high consumer demand or because the product deteriorates rapidly. Some fast moving consumer goods - such as meat, fruits and vegetables, dairy products and baked goods - are highly perishable. Other goods such as alcohol, toiletries, pre-packaged foods, soft drinks and cleaning products have high turnover rates. Fast moving consumer goods are products that have a quick shelf turnover, at relatively low cost and don't require a lot of thought, time and financial investment to purchase. The margin of profit on every individual Fast moving consumer goods product is less.

\section{Characteristics of FMCG in Nigeria \\ a. Branding:}

Creating strong brands is important for FMCG companies and they devote considerable money and effort in developing bands. With differentiation on functional attributes being difficult to achieve in this competitive market, branding results in consumer loyalty and sales growth.

\section{b. Distribution Network:}

Given the fragmented nature of the Indian retailing industry and the problems of infrastructure, FMCG companies need to develop extensive distribution networks to achieve a high level of penetration in both the urban and rural markets. Once they are able to create a strong distribution network, it gives them significant advantages over their competitors.

\section{c. Contract Manufacturing:}

As FMCG companies concentrate on brand building, product development and creating distribution networks, they are at the same time outsourcing their production requirements to third party manufacturers. Moreover, with several items reserved for the small scale industry and with these VAIDs units enjoying tax incentives, the contract manufacturing route has grown in importance and popularity.

\section{d. Large Unorganized Sector:}

The un-organized sector has a presence in most product categories of the FMCG sector. Small companies from this sector have used their location advantages and regional presence to reach out to remote areas where large consumer products have only limited presence. Their low cost structure also gives them an advantage.

\section{Theoretical Framework}

The study were backed up with the following theories psychoanalytic theory; Veblenian Social-Psychological Model, Theory of Reasoned Action and also with the following models the Nicosia Model and the Howard-Sheth Model;

\section{Psychoanalytic Theory}

Psychoanalytic theory traces back to Sigmund Freud, the Austrian founder of psychoanalysis. Although he himself was not concerned with consumer behaviour, his theories of human behaviour were revolutionary. $\mathrm{He}$ believed that humans are not able to fully understand their own motivations because the psychological factors that shape them are largely unconscious. A major part of the unconscious mind is comprised of strong urges and desires. Since these desires can cause significant guilt and shame when they surface, people will repress them. According to psychoanalytic theory, consumers respond to symbolic concerns as much as they respond to those of economics and function. Freud's work implies that external factors such as age and income cannot fully account for consumer behaviour because motivations lay deep in the psyche. Instead, marketing messages that 
contain an emotional appeal to consumers' feelings, hopes, aspirations and fears are often more effective than rational appeals (Kotler, 2002).

\section{Veblenian Social-Psychological Model}

Economist Thorstein Veblen suggested that humans are social creatures who conform to the standards of the culture and subgroups in which they live. He believed that people's individual needs and desires are created and influenced by group membership. Veblen focused his theory on members of society's "leisure class," whom he hypothesized were influenced by the desire for prestige rather than utilitarian need fulfillment. Although critics of Veblen's theory argue that it may be overstated in scope, the theory still proves useful. It suggests that marketers should understand the social influences that impact consumers in order to better comprehend product demand.

\section{Theory of Reasoned Action}

Created by Martin Fishbein and Icek Ajzen in the late 1960s, the Theory of Reasoned Action centers its analysis on the importance of pre-existing attitudes in the decision-making process. The core of the theory posits that consumers act on a behaviour based on their intention to create or receive a particular outcome. In this analysis, consumers are rational actors who choose to act in their best interests. According to the theory, specificity is critical in the decision-making process. A consumer only takes a specific action when there is an equally specific result expected. From the time the consumer decides to act, to the time the action is completed, the consumer retains the ability to change his or her mind and decide on a different course of action. Marketers can learn several lessons from the Theory of Reasoned Action. First, when marketing a product to consumers, marketers must associate a purchase with a positive result, and that result must be specific. Second, the theory highlights the importance of moving consumers through the sales pipeline. Marketers must understand that long lags between initial intention and the completion of the action allows consumers plenty of time to talk themselves out of a purchase or question the outcome of the purchase.

\section{The Nicosia Model}

According to Runyon \& Stewart (1987), the Nicosia model provides a sophisticated attempt to show the interrelationship between attributes of the consumer, the consumer decision-making process, the marketing communication of an organisation and feedback of the response of the consumer to the organisation. Schiffman \& Kanuk (1987) provide a simplistic explanation of the model by stating that it is interactive in design, where the organisation attempts to influence consumers through marketing actions and the consumers in return influence the organisation through their purchase actions (or lack of action if products are not purchased).

\section{FIGURE 2.3: THE NICOSIA MODEL OF CONSUMER DECISION-MAKING}

Field one: from the source of a message to the consumer's attitude

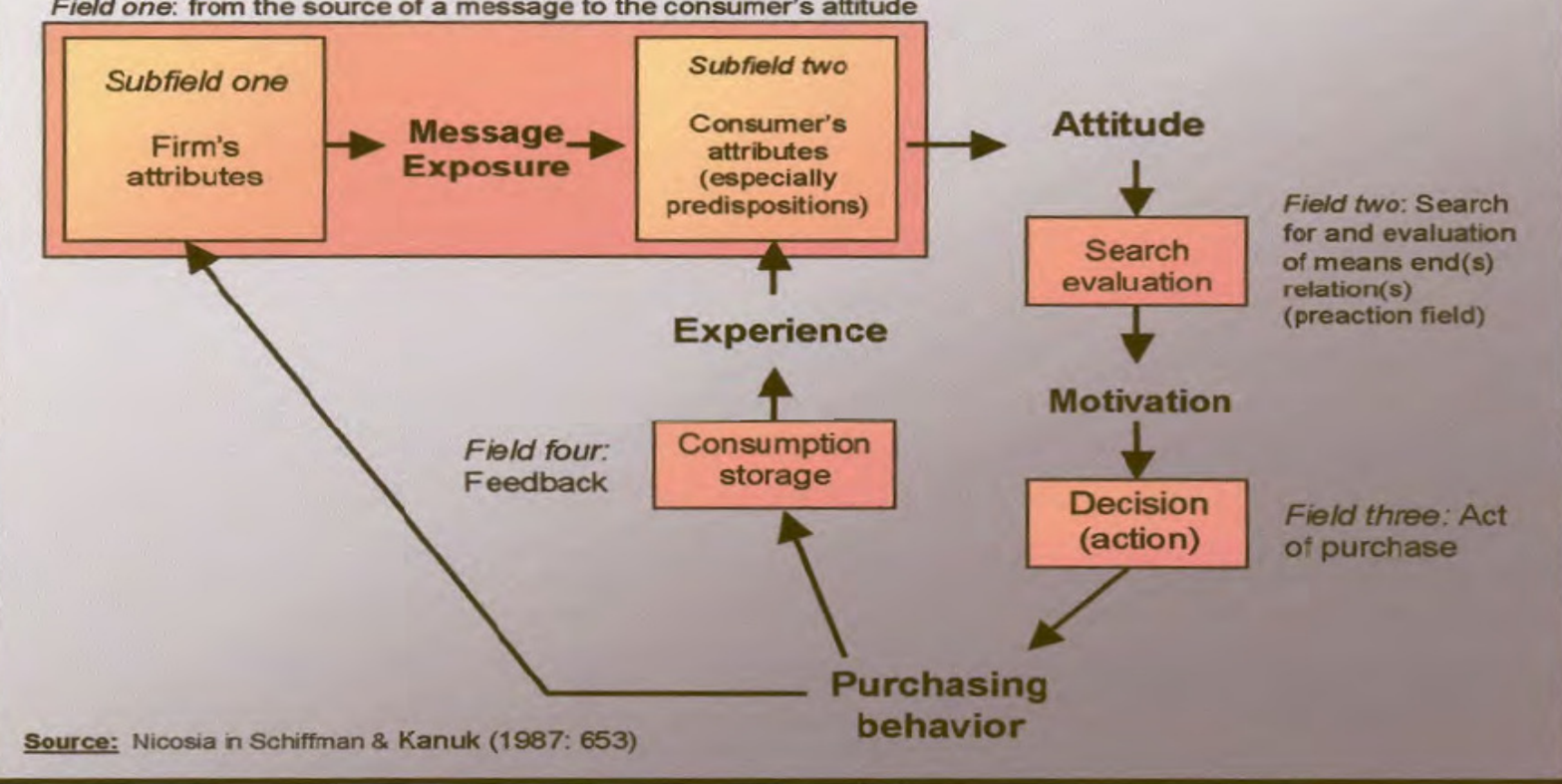

The Howard - -Sheth Model

The Howard-Sheth model of buying behaviour, according to Foxall (1990), presents a sophisticated integration 
of the psychological and various social and marketing influences on consumer choice, into a coherent sequence of information processing. Runyon Stewart (1987) and Foxall (1990) add respectively that the model attempts to explain rational brand choice behaviour within the constraints of incomplete information and limited individual capacities, and also that it provides an empirically testable description of behaviour in terms of cognitive functioning together with its outcomes. Schiffman \& Kanuk (1987) explain the Howard-Sheth model that explicitly distinguishes between three different stages or levels of decision-making, also referred to as levels of learning; namely extensive, limited and routinised problem-solving. Extensive problem-solving implies that the consumer has very little or no knowledge and beliefs about brands. The consumer actively seeks information on a number of alternatives at this point due to the lack of a brand preference. Foxall (1990) adds that in order to reduce brand ambiguity, the consumer is involved in a decision process and undertakes prolonged deliberation contemplating which brand to purchase or whether to buy at all.

\section{Empirical Review}

Singh and Singh (2014) carried out a study aims at identifying the factors affecting buying decisions of rural consumers and whether importance of these factors varies with age and income of respondents. The study analyze eight factors i.e. price, quality, warranty, advertisement, brand, friends recommendations, family members recommendation and packaging which rural consumers consider while making purchase decisions. 146 persons were interviewed and the data were analyzed with descriptive statistics. It was found that factors effect on rural consumer vary with age and income and found increasing with age and income. Friends and family members' recommendations had significantly more impact on buying decisions of lower income consumers than high income consumers. Packaging had significantly more impact on buying decision of lower income consumers than high income consumers.

Basha (2016) carried out a study to highlights the consumer behavior towards fast moving consumer goods in SPSR Nellore District of Andhra Pradesh. The objectives were to find out differences in the opinion of consumers on the basis of Age, educational qualification, location and gender regarding consumer behavior towards fast moving consumer goods in SPSR Nellore District of Andhra Pradesh.

Tanja (2015) conducted a study on different factors of consumer behavior effect on decision-making during coffee brand selection. Consumer behavior consists of four factors: cultural, social, personal and psychological. The objectives were limited only to social, personal and psychological factors. Data were collected by a selfadministered questionnaire. A link to the questionnaire was published on Facebook and shared among people. The quantitative research method was applied in his study. The result of the study has indications that social, personal and psychological factors have effect on a consumer's decision-making process when selecting a coffee brand. However, the result was not totally reliable due to the fact that credible correlation was missing.

\section{Research Methodology}

The study adopted survey design in order to analyze the examine the determinants of consumer purchasing decision making for fast moving consumer goods (A study of West African Tobacco Company products). This determinants are dynamic issues influencing consumer purchasing decision making for fast moving consumer goods. Thus, some methodological approaches have been employed by local/foreign authors to proffer solution to consumer purchasing decision making. However, this study adopts the methodology used by Tanja (2015), but with some major modifications.

\section{Model Specification and Operational Definition of Variables}

To some measures, consumer purchasing decision making was proxied by Turnover (TON) where used over the period while the determinants was measured by Psychological factors (Motivation, personality, perception, attitudes, learning) and Sociological factors (Social class, reference group, family, opinion leaders, culture/belief). Specifically, arising from the evidences in the empirical studies reviewed in chapter two above, we adopted the model as stated by Tanja (2015), but with modifications. Consequently, the functional form of the model specification will be:

For Hypothesis 1, we specify multiple regression model, thus;

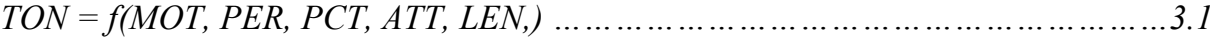

Explicitly, equation 1 can be written as:

$T O N_{i t}=b_{0}+b_{1} M O T_{i t}+b_{2} P E R_{i t}+b_{3} P C T_{i t}+b_{4} A T T_{i t}+b_{5} L E N_{i t}+\mu_{i t} \ldots \ldots \ldots \ldots \ldots \ldots . . . .2$

Where

$\mathrm{TON}_{i t}=$ Turnover as a proxy for consumer purchase decision making

MOT $_{i t}=$ Motivation; $P E R_{i t}=$ Personality; $P C T_{i t}=$ Perception; $A T T_{i t}=$ Attitude;

$L E N_{i t}=$ Learning; $\mathrm{b}_{0}=$ Intercept $; \mathrm{b}_{1}-\mathrm{b}_{5}=$ Parameters estimate $\mu_{i t}=$ Stochastic variables

For Hypothesis 2, we specify multiple regression model, thus;

$T O N=f(S O C, R E G, F A M, O P L, C U L)$ 
Explicitly, equation 1 can be written as:

$T O N_{i t}=b_{0}+b_{1} S O C_{i t}+b_{2} R E G_{i t}+b_{3} F_{A M} M_{i t}+b_{4} O P L_{i t}+b_{5} C U L_{i t}+\mu_{i t} \ldots \ldots \ldots \ldots \ldots \ldots . . . .4$

Where

$\mathrm{TON}_{i t}=$ Turnover as a proxy for consumer purchase decision making

$S O C_{i t}=$ Social class; $R E G_{i t}=$ Reference group; $F A M_{i t}=$ Family; $O P L_{i t}=$ Opinion leaders

$C U L_{i t}=$ Culture/belief; $\quad \mathrm{b}_{0}=$ Intercept $\mathrm{b}_{1}-\mathrm{b}_{5}=$ Parameters estimate; $\mu_{i t}=$ Stochastic variables

\section{Data Source and Measurement}

The data for the study was collected from distribution of thirty (30) structured questionnaires to students of MOUAU and annual financial statement of British American Tobacco Company...

\section{Data Presentation, Result and Discussion}

This study was carried out to analyze the determinants of consumer purchasing decision making for fast moving consumer goods (A study of British American Tobacco Company products). For the stated model, the dependent variable is turnover (TON). For the hypothesis 1, the independent are Psychological factors (Motivation, personality, perception, attitudes, learning) and for hypothesis 2, the independent are Social factors (Social class, reference group, family, opinion leaders, culture/belief).

\section{Test of Hypotheses}

Test of Hypothesis 1

$\mathbf{H}_{01}$ : Motivation, personality, perception, attitudes, learning have no significant impact on consumer purchasing decision making for FMCGs.

Dependent Variable: TON

Method: Least Squares

Date: 01/25/18 Time: 09:13

Sample: 130

Included observations: 30

\begin{tabular}{crrrr}
\hline \hline \multicolumn{1}{c}{ Variable } & Coefficient & Std. Error & t-Statistic & Prob. \\
\hline \hline MOT & 3.353420 & 1.583099 & 2.118263 & 0.0390 \\
PER & -0.331434 & 0.068653 & -4.827669 & 0.0004 \\
PCT & 1.539947 & 0.944028 & 1.631251 & 0.1328 \\
ATT & 2.601967 & 0.479270 & 5.429021 & 0.0001 \\
LEN & -4.838772 & 1.753632 & -2.759286 & 0.0097 \\
C & 12.22955 & 16.97953 & 0.720252 & 0.4783 \\
\hline \hline R-squared & 0.778974 & Mean dependent var & 39.06667 \\
Adjusted R-squared & 0.707931 & S.D. dependent var & 8.565904 \\
S.E. of regression & 8.531868 & Akaike info criterion & 7.302350 \\
Sum squared resid & 1747.027 & Schwarz criterion & 7.582590 \\
Log likelihood & -103.5353 & Hannan-Quinn criter. & 7.392001 \\
F-statistic & 10.46368 & Durbin-Watson stat & 2.002617 \\
Prob(F-statistic) & 0.000028 & & \\
\hline \hline
\end{tabular}

\section{Source: Researcher's computation using E-views 8.0}

As shown in Table 4.1 above, motivation (MOT) of 3.353420 shows that, a unit increase in motivation, holding other variables constant, will lead to increases in turnover by 0.0702699 units. This implies that, a percentage increase in motivation of consumers lead to increase in turnover. This implies that, motivating consumers' helps to inspire consumer purchase decision.

The coefficient of personality (PER) of 0.331434 shows that, a unit increase in personality, holding other variables constant, will lead to decreases in turnover by 0.331434 units. This implies that, a percentage increase in personality of consumers lead to decrease in turnover of the FMCGs. Thus, if a consumer advances in position his psychology about certain goods change automatically.

The coefficient of perception (PCT) of 1.539947 shows that, a unit increase in perception, holding other variables constant, will lead to increases in turnover by 1.539947 units. From the result, the t-cal value of 1.631251 which is less than t-tab value of 2.064. Thus, consumers psychological perception uphold to null hypothesis hence has no significant impact on turnover of the organization.

The coefficient of attitude (ATT) of 2.601967 shows that, a unit increase in attitude, holding other variables 
constant, will lead to increases in turnover by 2.601967 units. From the result, the t-cal value of 5.429021 which is greater than the t-tab value of 2.064. Thus, changes in consumers attitude leads to consumer patronage on fast moving goods.

The coefficient of Learning (LEN) of -4.838772 shows that, a unit increase in attitude, holding other variables constant, will lead to decreases in turnover by -4.838772 units. From the result, the t-cal value of 2.759286 which is greater than the $t$-tab value of 2.064 . This implies that, increase in consumer learning leads to decrease in consumption of West British Tobacco Company products.

The $\mathrm{R}^{2}$ which is the coefficient of determination was quite high with a value of 0.778974 which indicate as that $78 \%$ of the changes in the dependent variable can be explained by the changes in the independent variables while $22 \%$ can explained by the stochastic terms in model.. This implies that the independent variable (Motivation, personality, perception, attitudes, learning) can only explain 78 percent of changes in turnover, leaving $22 \%$ percent unexplained... Also, Durbin-Watson stat is 2.002617 and is close to 2.5 , this implies that there is no evidence of first-order autocorrelation. F-prob value of 0.000028 was observed from the analysis which is less than 0.05 , indicating that the estimated regression model adopted in this study is statistically significant at 5\% significant level. With this, the researcher alternative hypothesis thus, motivation and attitudes have positive and significant impact on turnover of fast moving goods while personality and learning negative and significant impact on turnover of fast moving goods. However, perception has positive and insignificant impact on turnover of fast moving goods in British American Tobacco Company in Nigeria.

\section{Test of Hypothesis 2}

Ho2: Social class, reference group, family, opinion leaders, culture/belief have no significant impact on consumer purchasing decision making for FMCGs.

Dependent Variable: TON

Method: Least Squares

Date: $01 / 25 / 18$ Time: $10: 18$

Sample: 130

Included observations: 30

\begin{tabular}{crrrr}
\hline \hline \multicolumn{1}{c}{ Variable } & Coefficient & Std. Error & t-Statistic & Prob. \\
\hline \hline SOC & 1.465141 & 0.230119 & 6.366884 & 0.0000 \\
REG & 2.807069 & 0.342869 & 8.187001 & 0.0000 \\
FAM & 1.339506 & 0.505385 & 2.650466 & 0.0325 \\
OPL & -3.692421 & 1.983079 & -1.861964 & 0.0749 \\
CUL & -0.088867 & 0.018859 & -4.712179 & 0.0001 \\
C & 18.35716 & 9.400762 & 1.952731 & 0.0626 \\
\hline \hline R-squared & 0.876308 & Mean dependent var & 39.06667 \\
Adjusted R-squared & 0.804979 & S.D. dependent var & 8.565904 \\
S.E. of regression & 5.383728 & Akaike info criterion & 6.381496 \\
Sum squared resid & 695.6287 & Schwarz criterion & 6.661735 \\
Log likelihood & -89.72244 & Hannan-Quinn criter. & 6.471147 \\
F-statistic & 9.882775 & Durbin-Watson stat & 2.031115 \\
Prob(F-statistic) & 0.000032 & & \\
\hline \hline
\end{tabular}

\section{Source: Researcher's computation using E-views 8.0}

From Table 4.2 above, social class (SOC) of 1.465141 shows that, a unit increase in social involvement, holding other variables constant, will lead to increases in turnover of British American Tobacco products by 1.465141 units. This implies that, consumer participation and registration in social activities leads to consumption of British American Tobacco Products. With this the null hypothesis is rejected and alternative accepted since t-cal value of 6.366884 is greater than t-tab value of 2.064 .

The estimate value of reference group (REG) of 2.807069 shows that, a unit increase in reference group, holding other variables constant, will lead to increases in turnover by 2.807069 units. By implication, reference group has positive and significant influence on consumer purchase decision making since the t-cal value of 8.187001 is greater than t-tab value of 2.064 .

The estimate of family (FAM) of 1.339506 shows that, a unit increase in family, holding other variables constant, will lead to increases in turnover of British American Tobacco products by 1.339506 units. From the result, the $t$-cal value of 2.650466 which is greater than $t$-tab value of 2.064 . Thus, the decision of the family and family consumption pattern has a significant impact consumer purchase decision making in fast moving consumer goods... 
The coefficient of opinion leaders (OPL) of -3.692421 shows that, a unit increase in opinion leaders, holding other variables constant, will lead to increases in turnover by -3.692421 units. However, most of the consumer wish to behave according to some certain people in the society and as a result, copy the attitudes and lifestyle. Thus, if a consumer copy the life of a good opinion leader his consumption pattern might change in good or bad way. From the result, the t-cal value of 1.861964 which is less than the t-tab value of 2.064. In effect, opinion leaders has significant influence on consumer purchase decision making in FMCGs.

The coefficient of culture/belief (CUL) of -0.088867 shows that, a unit increase in culture/belief, holding other variables constant, will lead to decreases in turnover of British American Tobacco Company by -0.088867 units. From the result, the t-cal value of -4.712179 which is greater than the t-tab value of 2.064. This implies that, cultural belief among consumer prohibits consumption of certain goods.

The $\mathrm{R}^{2}$ which is the coefficient of determination was quite high with a value of 0.876308 which indicate as that $88 \%$ of the changes in the dependent variable can be explained by the changes in the independent variables while $12 \%$ can explained by the stochastic terms in model.. This implies that the independent variable (Social class, reference group, family, opinion leaders, culture/belief) can only explain 88 percent of changes in turnover, leaving $12 \%$ percent unexplained... Also, Durbin-Watson stat is 2.031115 and is close to 2.5, this implies that there is no evidence of first-order autocorrelation. F-prob value of 0.000032 was observed from the analysis which is less than 0.05 , indicating that the estimated regression model adopted in this study is statistically significant at 5\% significant level. With this, the researcher alternative hypothesis thus, Social class, reference group, family have positive and significant impact on turnover of British American Tobacco Company fast moving products; while culture/belief negative and significant impact on turnover of fast moving goods. However, opinion leaders has negative and insignificant impact on turnover of fast moving goods in British American Tobacco Company in Nigeria.

\section{Conclusion}

The behaviour of a consumer plays an important role in marketing of fast moving consumer goods. This behaviour is effected by various factors. In the present era of globalization needs and wants of consumers changes with time. In effect, the core concept of this study is to analyze the factors affecting consumer purchase decision making in fast moving consumer goods (FMCG). The study adopts and examine the psychological and sociological factors consumer purchase decision making. From the psychological aspect, the result reveal that motivation and attitudes have positive and significant impact on turnover of fast moving goods while personality and learning negative and significant impact on turnover of fast moving goods. However, perception has positive and insignificant impact on turnover of fast moving goods in British American Tobacco Company in Nigeria. More so, the sociological result shows that Social class, reference group, family have positive and significant impact on turnover of British American Tobacco Company fast moving products; while culture/belief negative and significant impact on turnover of fast moving goods. However, opinion leaders has negative and insignificant impact on turnover of fast moving goods in British American Tobacco Company in Nigeria. In conclusion, since Fast Moving consumer goods are those goods that are consumed every day by the average consumer and are replaced or fully used up over a short period of days, weeks, or months, and within one year. Marketers of this products need study the critical factors affecting consumer purchase decision making in order to satisfy, retain and maintain the ultimate and prospective consumers.

\section{REFERENCES}

Agarwal, S. K. (2013). A study of consumer behaviour of FMCGs products in Madhya Pradesh, International Journal of Business and Management Research, Vol. 4, Issue 1, Jan. 2014.

Basha, A.M. M. (2016) A study on consumer behaviour towards FMCG goods an empirical study with special reference to SPSR Nellore district of Andhra Pradesh. Business Management Vikrama Simhapuri University SPSR Nellore, Andhra Pradesh, (India)

Berry, L. (2000). Cultivating service brand equity. Journal of the Academy of Marketing Science, Vol. 28 (1), 17-23.

Blackwell Roger D., Miniard Paul W. and Engel James F. (2001). Consumer Behaviour. Thomson. South Western.

Chauhan, S. V. and Singh, A. (2014). Teenagers' influence in Family Buying Decision Making of FMCG Products: A Case Study of Rural Market. International Journal of Management and Social Sciences Research (IJMSSR) 3 (2), 17-26.

Frank, H. J. (2012). A review of recent research on consumer behavior, in Clark, L.H. (Ed.), Consumer Behavior: Research on Consumer Reactions, Harper, New York, pp. 93-218.

Kardes, F., Cline, T. and Cronley, M. (2011). Consumer behavior: Science and Practice. South-Western Cengage Learning.

Khan, M. 2006. Consumer Behaviour and Advertising Management. New Age International. 
Kotler, P. (2002). Marketing management, the Millenium Edition, New Delhi, Prentice-Hall of India, pp. 159-84

Kotler, P. and Armstrong, G. (2010). Principles of Marketing. Pearson Education. Thirteenth Edition. New Jersey.

Kotler, P., Keller, K. L., Koshy, A. and Jha, Mithileshwar (2005). Marketing management. A

Kundi, J. (2008). Dimensions of brand personality. Journal of Marketing Research. Volume 34. American Marketing Association.

Nicosia, F. and Robert, M. (1976). Toward a Sociology of Consumption." Journal of Consumer Research 120 (42) $12-34$

Perreau, F. (2014). The Consumer Factor. The Consumer Buying Decision Process. http://theconsumerfactor.com/en/5-stages-consumer-buying-decisionprocess/ Accessed on 29 December 2014.

Shalini, S. (2013), Factors Affecting Buying Behaviour of Consumers in Unauthorized Colonies for FMCG Products, Global Journal of Management and Business Studies. ISSN 2248-9878, 3(7), 785-792.

Sheth, J. (1982). Consumer Behavior: Shortage and Surpluses." in Adyances in Consumer Research, Volume 9 , ed. Andrew Mitchell, Ann Arbor, MI: Association for Consumer Research, 13-16.

Solomon, M. (2014). Consumer behavior. Sixth edition. Prentice Hall.

Solomon, M. R. and Nancy, K. P. (2014). Consumer behavior: buying, having and being, 7th edition Prentice Hall.

Solomon, M. R. Bamossy, G. and Askegaard, S. (2009). Consumer behavior: A European perspective, Prentice Hall. South Asian Perspective".13 ed., Pearson Education, New Delhi.

Sproles, G. B. and Kendell, W. J. (2006). The economics of fashion. In fashion: Consumer behavior toward dress. (pp.83-96). Minneapolis: Burgess.

Tanja, L. (2015). Factors affecting consumers' buying decision in the selection of a coffee brand. Thesis summited to Faculty of Business Administration in Saimaa University of Applied Sciences, Lappeenranta

Wright, P. L. (2016). Consumer choice strategies: Simplifying vs. Optimising, Journal of Marketing Research, February, 60-67. 